\title{
Empirical Formulas to Predict the Axial Capacity of Driven Piles Using in-Situ Dynamic Load Testing Data
}

\author{
Anis Shatnawi, Wassel AL Bodour, Mu'tasim Abdel-Jaber, and Bashar Tarawneh
}

\begin{abstract}
Accurate estimation of the axial capacity of driven piles is crucial and leads to more economical design. In this research, Artificial neural networks (ANNs) and regression analysis (RA) have been used to develop empirical formulas to estimate piles' axial capacity using experimental dynamic load testing data. The RA model was further improved using a nonlinear fitting software "Eureqa", based on artificial programming. Three input variables were used to build the formulas; these variables are pile cross-sectional area, friction angle at pile tip, and effective stress at pile tip. Simplified mathematical expressions are presented to be used as empirical formulas to estimate piles' axial capacity. An optimize formula was developed using ANNs; it has a coefficient of determination $\left(R^{2}\right)$ of 0.92 , root mean square error (RMSE) of 478.11, and mean absolute error (MAE) of 366.67. On the other hand, the improved RA formula has R2 of 0.86, RMSE of 450.1, and MAE of 416.91. The results indicated that the predictions of ANNs formula are in close agreement with the experimental data.
\end{abstract}

Index Terms-Axial capacity, driven piles, neural network, regression.

\section{INTRODUCTION}

Piles are structural members that are made of steel, concrete, or timber. They are more expensive than shallow foundations. In spite of their cost, utilizing piles is often necessary to meet structural loading conditions. Piles are used to transfer surface loads to lower levels in the soil mass. The load transfer mechanism may be a vertical distribution of the load along the pile or a direct application of pressure to a deeper layer through the pile point. A vertical distribution of the load is made using a friction pile, and a direct load is made by a point, or end bearing pile.

Most piles carry the load as a mixture of side resistance and end-bearing with the exception when the pile penetrates a significantly soft soil to a solid base. Vertical distribution of the load is made using a

Estimation of the pile's load carrying capacity is a significant factor in the design and construction of driven piles. It is essential to calculate the required cross-section and length of the pile based on the loading of the superstructure, allowable stress of the pile material, and the in-situ soil parameters. Analytical and empirical estimation of axial capacity of piles based on soil properties has improved significantly. However, the results are still questionable because of many issues such as soil profile

Manuscript received November 9, 2018; revised February 27, 2019.

All authors are with the Civil Engineering Department at the University of Jordan, Amman, Jordan (Corresponding author: Bashar Tarawneh; email: btarawneh@ju.edu.jo). inconsistency, interpretation of geotechnical exploration data, and various assumptions used in the calculation methods in addition to disturbance during the driven pile installation.

Static load test (STL) is considered the best available method to estimate the ultimate capacity of piles. However, the SLT is not preferred by geotechnical engineers because of its high cost and time-consuming. In some circumstances such as a very soft soil near the surface and marine environment, the test is uncontrollable due to the large pile setup.

Dynamic formulas were introduced to estimate the capacity of driven piles. However, the methods are inexact due to the simplicity in representing the driving system, soil-pile-structure interaction, and the distribution of soil friction along the pile. Therefore, most design codes require many SLT, as required by the ASTM-D5780-10, to be implemented during the pile driving production phase to guarantee the actual capacity of the piles.

High strain dynamic pile test (HSDPT) was formed to produce data on strain or force and acceleration of a driven shaft when subjected to impact load. The collected data is employed to estimate the bearing capacity and the structural integrity of the driven pile as well as hammer performance, pile stresses and soil properties such as damping coefficients and quake values. The procedure is regulated in the ASTMD4945-08.

When determining the axial capacity, geotechnical engineers have been using Pile Driving Analyzer (PDA) combined with Case Pile Wave Analysis Program (CAPWAP) software which is the most widely used method for HSDPT because it is simple and can quickly handle data.

Likins et al. [1] concluded that, if performed and interpreted correctly, the high strain dynamic restrike testing with CAPWAP analysis can provide agreement with the results of SLT regarding design capacity.

Many researchers have utilized artificial neural networks (ANNs) and regression analysis (RA) as tools to develop predictive models for various geotechnical engineering problems. Tarawneh [2] employed ANNs to estimate the Nvalue of the standard penetration test (SPT) using the cone penetration test (CPT) results. Tarawneh [3] used ANNs to forecast post installation setup of pipe piles. Tarawneh and Imam [4] employed ANNs and RA to estimate pile setup for three-pile types (pipe, concrete, and H-pile).

Tatari et al. [5] employed ANNs to evaluate the existing conditions of culverts using inventory data presented by [6], [7], [8]. Tarawneh and Nazzal [9] employed RA and ANNs to optimize the prediction of subgrade resilient modulus design input from falling weight deflectometer test results. Ornek et al. [10] presented a study to describe the 
application of artificial neural networks (ANNs), and the multi-linear regression model (MLR) to determine the bearing capacity of shallow circular foundation carried by layers of compacted granular fill over natural clay soil. Nejad et al. [11] developed an ANN model to predict pile settlement based on standard penetration test data. AbuKiefa [12] introduced three neural network models to predict the capacity of driven piles in granular soils.

In this research, ANNs and RA are applied to predict the axial capacity of driven piles. The purposes of the study are to:

- Compile driven piles' axial capacity dynamic load test data from the published literature.

- Develop formulas to predict driven pile's axial capacity using ANNs RA.

- Provide a simplified mathematical expression of the developed formulas.

\section{DATASET}

A dataset was assembled from the results of 162 driven pile dynamic load tests. The data were collected from the published literature. The references used to compile the database are shown in Table I. The collected data included the axial capacity of driven pile in $\mathrm{kN}(Q)$, pile length in meter $(L)$, pile cross-sectional area in $\mathrm{m}^{2}(\mathrm{~A})$, friction angle along the pile in degrees $\left(\phi_{s}\right)$, friction angle at pile tip in degrees $\left(\phi_{t}\right)$, and effective stress at pile tip in $\mathrm{kN} / \mathrm{m}^{2}\left(\sigma^{\prime}\right)$.

\begin{tabular}{ll}
\multicolumn{2}{c}{ TABLE I: DATABASE REFERENCES } \\
\hline \hline Reference & No. of Testing \\
\hline Tarawneh [3] & 44 \\
Khan and Decapite [13] & 20 \\
Thompson et al. [14] & 58 \\
Komurka [15] & 6 \\
Dover and Howard [16] & 11 \\
Holloway and Beddard [17] & 5 \\
Antorena and McDaniel [18] & 4 \\
Goble et al. [19] & 6 \\
Tavenas [20] & 8 \\
\hline \hline
\end{tabular}

The friction angle of the soil along the pile shaft and near the pile tip provides information about the shear strength of the surrounding and supporting soils. Effective stress at the tip of the pile has a significant role in calculating the pile capacity. Pile length and the cross-sectional area provides the necessary information about pile dimensions.

\section{ANNS AND REGRESSION INPUTS, OUTPUT, AND PERFORMANCE CRITERIA}

To achieve accurate pile axial capacity predictions, a thorough understanding of the factors affecting axial capacity is needed. Most of the traditional pile axial capacity methods include the following fundamental parameters: pile geometry, effective stress at pile tip, and soil properties.

To evaluate the developed formula, a performance criterion was established using the mean absolute error (MAE), root-mean-square error (RMSE), and the coefficient of determination $\left(R^{2}\right)$. The aim is to develop a formula with higher $R^{2}$ value and least MAE and RMSE. The equations of these performance criteria are given in equation (1) and (2) below:

$$
\begin{gathered}
M A E=\frac{1}{n} \sum_{i=1}^{n}\left|e_{i}\right| \\
R M S E=\sqrt{\frac{1}{n} \sum_{i=1}^{n} e_{i}^{2}} \\
R^{2}=1-\frac{\sum_{i=1}^{n} e_{i}^{2}}{\sum_{i}^{n}\left(Q_{i}-\bar{Q}\right)^{2}}
\end{gathered}
$$

where $n$ is the total number of collected data points, $e_{i}$ is differences between measured $\mathrm{s}$ and predicted values. $Q_{i}$ is actual axial capacity values, and $\bar{Q}$ is the average of the measured values.

\section{DIVISION AND PRE-PROCESSING OF THE DATA}

In this research, the data were randomly split into two statistically consistent sets( training and testing ). $80 \%$ of the data were used for training, and $20 \%$ were employed for testing the developed model. The training data is used to train the model. The test data is used to measure the performance of the chosen ANNs and RA formulas. The data employed for training and testing should represent the corresponding population [21]. The statistical properties (e.g., range, mean, and standard deviation) of the training and testing data should be alike [22].

TABLE II: DATABASE STATISTICS

\begin{tabular}{llllll}
\hline \multicolumn{1}{c}{ Variable } & \multicolumn{1}{c}{ Mean } & Standard Deviation & \multicolumn{1}{c}{ Min. } & Max. & Range \\
\hline Pile cross sectional area in $\mathrm{m}^{2}, A$ & 0.156 & 0.12 & 0.00613 & 0.666 & 0.66 \\
Pile length in $m, L$ & 18.33 & 8.05 & 2.987 & 47.213 & 44.226 \\
Friction angle at pile tip, $\phi_{t}$ & 36 & 2.44 & 29 & 41 & 12 \\
Friction angle along the pile, $\phi_{s}$ & 34.4 & 2.36 & 28 & 39 & 11 \\
Effective stress $\left(\mathrm{kN} / \mathrm{m}^{2}\right), \sigma$ & 175.5 & 82.23 & 38 & 475 & 437 \\
Axial capacity of the pile $(\mathrm{kN}), Q$ & 2154.15 & 1191.38 & 75.18 & 5604.31 & 5529.13 \\
\hline \hline
\end{tabular}

Also, developed formulas perform best when they do not extrapolate beyond the range of their training data [23], [24]. Therefore, to develop the finest possible model, all patterns that are contained in the data need to be included in the training set. To accomplish this, several random combinations of the training and testing sets were used until a statistically consistent data set was obtained. The statistical parameters examined include the mean, standard deviation, minimum, maximum and range, as suggested by
[25] are shown in Table II. In general, the statistics are in good agreement, and the dataset can be used to represent the same population.

\section{REGRESSION ANALYSIS (RA)}

A complete statistical analysis was carried out to develop a regression model that better the axial pile capacity. RA is a collection of statistical methods for predicting the relations 
between variables. It involves many procedures for modeling and investigating several variables to find the correlation between a dependent and one or more independent variables. RA helps in understanding how the value of the dependent variable varies when any of the independent variables is varied, while the other independent variables are kept fixed. $Q$ is used as the dependent variable. $L, A, \phi_{s}, \phi_{t}$, and $\sigma$ were used as the independent variables.

A multivariable linear stepwise RA was conducted to find the relevant independent variables that influence forecasting pile's axial capacity. The stepwise technique was applied to the collected data. In this method, independent variables elimination is based on two statistical tests( t-test and F-test) results. Forward and backward procedures are blended in the process.

Stepwise technique fits all possible linear models and selects the one with the highest F-test statistic value. During the process, at every step, a variable is excluded if its significance level drops lesser than the defined criteria. Excluding insignificant independent variables yields a more precise prediction [26]. The process is stopped when no more independent variables outside the model have the needed level of significance to enter the model.

However, at each stage of the procedure, the deletion of early selected independent variables is permitted. To eliminate the insignificant variables, the regression statistics used are significance level ( $\mathrm{P}$ value less than 0.05 ).

\section{A. Regression Analysis Results}

TABLE III: REGRESSION ANALYSIS OUTPUT

\begin{tabular}{ccccccc}
\hline \hline No. & Model & Coefficient & $\begin{array}{c}\text { P-value } \\
\text { (Significance) }\end{array}$ & $\boldsymbol{R}^{2}$ & MAE & RMSE \\
\hline \multirow{2}{*}{1} & Constant & 1304.67 & 0.0001 & & & \\
& $\mathrm{~A}$ & 5459.15 & 0.0001 & 0.29 & 799.8 & 995.7 \\
& Constant & -7194.60 & 0.0001 & & & \\
2 & $\mathrm{~A}$ & 5512.58 & 0.0001 & 0.53 & 631.5 & 814.87 \\
& $\phi_{\mathrm{t}}$ & 236.06 & 0.0001 & & & \\
& Constant & -7901.70 & 0.0001 & & & \\
3 & $\mathrm{~A}$ & 5843.69 & 0.0001 & & & \\
& $\phi_{\mathrm{t}}$ & 225.59 & 0.0001 & 0.7 & 504.2 & 660 \\
& $\sigma^{\prime}$ & 5.88 & 0.0001 & & & \\
\hline \hline
\end{tabular}

The results of the stepwise linear multivariable RA are provided in Table III. The Coefficients represent the weights used for the independent variables in the prediction model. RMSE, MAE, and $R^{2}$ values are provided for each model. It can be noted that model 3 has the highest $R^{2}$ value 0.7, the least MAE (504.18) and RMSE (660). Model 3 is considered the best one among the developed models. As summarized in Table III, Model 3 is presented in equation (4) as shown below:

$$
\boldsymbol{Q}=-7901.7+5843.69 \boldsymbol{A}+22.59 \emptyset_{t}+5.88 \boldsymbol{\sigma}^{\prime}
$$

The linear multivariable RA results showed that only three independent variables ( $A, \phi_{t}$, and $\sigma^{\prime}$ ) are statically significant $(P<0.05)$. However, two independent variables $\left(L\right.$ and $\left.\phi_{s}\right)$ are eliminated because they are insignificant $(P>$ $0.05)$. It should be noted that $\phi_{s}$ is considered a soil parameter along the pile depth and $L$ represents the pile length. However, $\sigma$ which represents the effective stress at pile tip is a significant independent variable which is calculated by multiplying the pile length by the submerged unit weight of the soil. So, the pile length is included in the effective stress calculations. On the other hand, the submerged unit weight of the soil is highly correlated with $\phi_{s}$ along the pile depth $\left(R^{2}=0.65\right)$. Therefore, $\sigma$ appeared as a significant variable because it includes $L$ and $\phi_{s}$ indirectly.

\section{B. Improved Regression Model}

Further improvement to the regression analysis is carried out using a nonlinear fitting software "Eureqa," based on artificial programming. The software was used to find a general function using the significant independent variables $\left(A, \phi_{t}\right.$, and $\left.\sigma^{\prime}\right)$ to predict the pile's axial capacity $(Q)$. The software searches for a formula by combining mathematical building-blocks (e.g., addition, subtraction, multiplication, division, exponential, and power). As mentioned earlier, $80 \%$ of the data was used to build the function and $20 \%$ to test it. The software does not require a predefined formula for variables fitting. Instead, the software fitting tool creates generations of equations. A review of artificial programming techniques can be obtained from [27], [28].

\begin{tabular}{ccccc}
\multicolumn{5}{c}{ TABLE IV: EUREQA SOFTWARE OUTPUT } \\
\hline \hline No. & Model & $\boldsymbol{R}^{2}$ & MAE & RMSE \\
\hline \multirow{2}{*}{1} & $\mathrm{Q}=1822.45+1904.57 \mathrm{~A}+$ & & & \\
& $0.553 \phi_{\mathrm{t}}+0.068 \sigma^{\prime}-6645.98 \mathrm{~A}^{2}$ & 0.86 & 416.91 & 450.11 \\
& & & & \\
2 & $\mathrm{Q}=2057.18-0.4 \sigma^{\prime}-0.78 \phi_{\mathrm{t}} \mathrm{A}$ & 0.84 & 456.75 & 514.78
\end{tabular}

The results of the developed models using Eureqa software are shown in Table IV. The output of the software led to two models that outperformed the RA based on the performance criteria $\left(R^{2}\right.$, MAE, RMSE). Formula 1 has the highest $R^{2}$ value of 0.86 , the lowest MAE and RMSE of 416.91 and 450.11 , respectively. It can be seen that the results of Eureqa pointed improvement to the developed linear regression model.

\section{ARTIFICIAL NEURAL NETWORKS (ANNS)}

ANNs are neurons linked with connections defined by their weights. The distinctiveness of artificial networks is that they are not programmed but trained. To create the ANNs model, two data sets are needed. The first set is for training and the second one is a testing set which is required to establish the efficiency of the trained model. An essential aspect of neural network modeling is the determination of weights applied during network training. There are several methods of training. One of the regularly used methods is a generalized delta rule or error back-propagation algorithm which is reported in detail by [29].

The back-propagation algorithm is used for optimizing the connection weights in this study, whereas the Levenberg- Marquardt (LM) algorithm was used as a learning rule. LM is one of the best higher-order adaptive algorithms recognized for reducing the error of a neural network [30].

A typical ANN is shown in Fig. 1. Neuron $u_{i}$ is linked with a few neurons which send their output signal $\left(o_{k, j, 1}\right)$ to the neuron $\left(u_{i}\right)$. Output signals are multiplied by weights 
$\left(w_{i j}\right)$. A signal $\left(b_{i}\right)$ is added to the sum of weighted signals. This gives the value of the signal of the neuron $\left(u_{i}\right)$. Then the produced function $(f)$ copies the value to the output signal $\left(o_{i}\right)$ of the neuron $\left(u_{i}\right)$. Connections between neurons and the output function may be synchronized in advance [31].

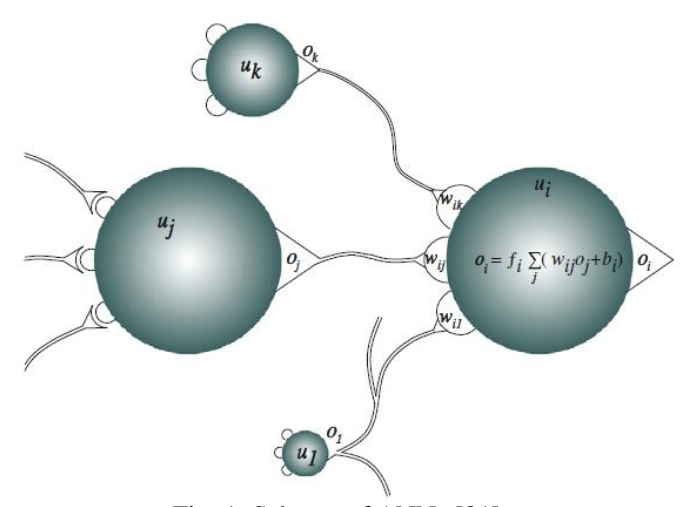

Fig. 1. Scheme of ANNs [31].

The symbols in Fig. 1 have the following definitions: $u_{i}$ value of neuron $i$, $u_{j}$ value of neuron $j$, $u_{k}$ value of neuron $k$, $u_{1}$ value of neuron 1 , $w_{i j}$ weight of interaction between neurons $i$ and $j$, $w_{i k}$ weight of interaction between neurons $i$ and $k$, $w_{i 1}$ weight of interaction between neurons $i$ and 1 , $b_{i}$ threshold of neuron $i$,

$f_{i}$ output function, $o_{i}$ output signal of neuron $i$, $o_{j}$ output signal of neuron $j$, $o_{k}$ output signal of neuron $k$, $o_{1}$ output signal of neuron 1 .

The generalized delta rule [29] which is the error backpropagation is summarized in the equation (5) and (6). alteration in weights is relative to the derivative of the error of neuron which is assessed in a different way for the output and the hidden layers of neurons. The learning stage of ANNs is influenced by several parameters, such as the maximum number of iterations, learning step size, an output function, maximum permitted error geometry of the network and data.

$$
\Delta p w_{j i}=\eta \delta_{p j} o_{p i}
$$

$\delta_{p j}$

$\left\{\begin{array}{l}f_{j j}^{\prime}\left(\text { net }_{p j}\right)\left(t_{p j}-O_{p j}\right) \text {; weights for output neurons, } \\ f_{j}^{\prime}\left(\text { net }_{p j}\right) \sum_{k} \delta_{p k} w_{k j} ; \text { weight for neurons on hidden layers }\end{array}\right.$

Feed-forward neural networks with error backpropagation learning algorithm have been used to estimate pile's axial capacity. The learning stage of the ANNs depends on several parameters, such as learning step size, the maximum number of iterations, geometry of the network and, most importantly, the data. Taking into account the geometry of the ANNs, it cannot be accurately defined which one corresponds to the exact data. Therefore, it was decided to use different network geometries as shown in the next section of this paper.

\section{A. Development of the ANN Model}

To build an ANN model, it is required to determine the model inputs and outputs, division and pre-processing of the existing data, optimization of a network, model validations, and stopping criteria. Neuro-Solutions 6.0 Software was employed in developing the neural network model. This software combines a modular design interface with advanced learning procedures, giving the strength and adaptability required to design the neural network that produces the best solution.

The data used to develop and validate the neural network model were obtained from both published literature. Suitable case studies were those having pile load tests and information regarding the piles and soil. The database contains a total of 162 cases of pile dynamic load tests. The references used to compile the database are presented in Table I.

\section{B. ANN Model Architecture}

Choosing the network architecture is a crucial and challenging task in ANN model development [32]. It needs the selection of the optimum number of hidden layers and the number of nodes in each layer. There is no theory to determine the best ANN architecture [33]. The number of nodes in the input and output layers is constrained by the number of model inputs and outputs. A total of three input variables are included in developing the ANN model, namely, pile cross-sectional area $(A)$, friction angle at pile tip $\left(\phi_{t}\right)$, and effective stress at pile $\operatorname{tip}(\sigma)$. Only three variables are used because they are statistically significant. The output layer possesses a single node which is the measured value of the axial capacity of the pile.

Numerous network structures with different numbers of hidden layers and nodes in the hidden layer were trained and tested. This method was selected to find the optimal network architecture from various trials. It has been proved that a network with one hidden layer can approximate any continuous function [34].

In this paper, one hidden layer was employed. To achieve the best network geometry, ANNs with a single hidden layer and a varying number of elements, in the hidden layer, are trained using sigmoidal (Sig.) and hyperbolic tangent (tanh) transfer functions for the hidden and output layers. Combinations of numbers of nodes in the hidden layer and various types of the transfer function that produced the best forecasts of pile's axial capacity are displayed in Table V.

The training set is utilized to modify the connection weights, while the testing set checks the capability of the model to generalize. The performance of the model is examined at several stages during the training process, and training is stopped when the error of the testing set starts to increase [25].

The performance of the trained ANN model should be validated using data sets that have not been used as part of the learning process. This dataset is known as the testing set. The goal of the model validation phase is to ensure that the model can generalize within limits robustly placed by the training data [25]. Table 6 shows the RMSE, MAE, and R values for the developed ANN models. It is clear that model 4 has the highest R-value and the lowest RMSE and MAE. 
TABLE V: ANNS MODELS STRUCTURE

\begin{tabular}{|c|c|c|c|c|c|}
\hline Model No. & Model name & Input nodes & No. of elements in the hidden layer & No. of elements in the output layer & Transfer function \\
\hline 1 & Ann-5-2-1-Sig & 5 & 2 & 1 & Sig. \\
\hline 2 & Ann-5-2-1-tanh & 5 & 2 & 1 & $\tanh$ \\
\hline 3 & Ann-5-3-1-Sig & 5 & 3 & 1 & Sig \\
\hline 5 & Ann-5-4-1-Sig. & 5 & 4 & 1 & Sig. \\
\hline 6 & Ann-5-4-1-tanh & 5 & 4 & 1 & $\tanh$ \\
\hline 7 & Ann-5-5-1-Sig. & 5 & 5 & 1 & Sig \\
\hline 8 & Ann-5-5-1-tanh & 5 & 5 & 1 & $\tanh$ \\
\hline
\end{tabular}

TABLE VI: R, RMSE AND MAE FOR THE ANN MODELS

\begin{tabular}{crrrr}
\hline \hline \multirow{2}{*}{ Model No. } & \multirow{2}{*}{ Model name } & \multicolumn{3}{c}{ Testing data set } \\
\cline { 3 - 5 } 1 & Ann-5-2-1-Sig & 684.16 & 510.03 & 0.49 \\
2 & Ann-5-2-1-tanh & 646.39 & 592.65 & 0.52 \\
3 & Ann-5-3-1-Sig & 1011.2 & 791.21 & 0.34 \\
4 & Ann-5-3-1-tanh & 478.11 & 366.47 & 0.92 \\
5 & Ann-5-4-1-Sig. & 1437.77 & 937.5 & 0.44 \\
6 & Ann-5-4-1-tanh & 1180.57 & 856.78 & 0.38 \\
7 & Ann-5-5-1-Sig. & 769.57 & 587.4 & 0.46 \\
8 & Ann-5-5-1-tanh & 581.0 & 442.22 & 0.71 \\
\hline \hline
\end{tabular}

\section{ANN Results}

Table III and Table IV show the structure and results of the developed ANN best performing models. The results showed that the RMSE values were between 478.11 and 1437.77, the MAE values were between 366.47 and 937.5, and the coefficient of determination, $R^{2}$, values were between 0.34 and 0.92 for the testing data set. It is remarked that model 4, which used three nodes in the hidden layer and tanh as the transfer function for both hidden and output layer was the best model based on the performance criteria $\left(R^{2}, \mathrm{MAE}, \mathrm{RMSE}\right)$. It has the highest $R^{2}$ value $(0.92)$, the lowest RMSE (478.11) and MAE values (366.47) for the testing data set. The mathematical expression of the developed ANN model 4 algorithm is presented below in equations (7), (8), (9), and (10):

$$
Q=2739.73\left[\operatorname { t a n h } \left(-10.643 \boldsymbol{X}_{1}+6.767 \boldsymbol{X}_{2}+0.027 \boldsymbol{X}_{3}+\right.\right.
$$

where $X_{1}, X_{2}$, and $X_{3}$ can be calculated using the equations below:

$$
\begin{aligned}
& X_{1}=\tanh \left(0.0695 \emptyset_{t}+0.0024 \sigma^{\prime}-0.1728 A+3.0824\right)(8) \\
& X_{2}=\tanh \left(0.0594 \emptyset_{t}+0.004 \sigma^{\prime}+0.4236 A+1.8013\right) \\
& X_{3}=\tanh \left(-0.9471 \emptyset_{t}+0.0217 \sigma^{\prime}+7.4745 A+70.927\right.
\end{aligned}
$$

The results of the ANNs showed that there is a strong correlation between the actual and ANNs predicted axial capacity. It is clear that the value of $R^{2}$ represents an excellent fit.

\section{SUMMARY AND CONCLUSIONS}

In this study, RA and ANNs were used to develop formulas to predict the axial capacity of driven piles. The RA model was further improved using a nonlinear fitting software "Eureqa," based on artificial programming. A database was assembled from the results of 162 driven pile dynamic load tests. The data were obtained from the published literature.

Five input variables were investigated, however, three of them were used to develop the formulas because they are statistically significant. Those variables are pile crosssectional area (A), friction angle at pile tip $\left(\phi_{t}\right)$, and effective stress at pile $\operatorname{tip}\left(\sigma^{\prime}\right)$. To evaluate the generated models, a performance criterion was established using RMSE, MAE and the $R^{2}$. The goal was to develop a formula with higher $R^{2}$ value and least RMSE and MAE. Several models were produced as shown in Tables III, IV, V, and VI.

ANN model 4 has the highest $R^{2}$ value and the lowest RMSE and MAE. The mathematical expression of the best performing ANN algorithm is presented in equations (7) through (10). Based on the available data and result, this formula can be recommended to predict the pile's axial capacity. The suggested ANNs method uses feed-forward neural networks with the error back-propagation algorithm. It should be noted that the ANN modeling is based on experimental data and is appropriate for use in an interpolative method. Similar to all empirical formulas, the range of applicability of the ANN-based equation is limited by the data used to build and calibrate the model. To improve the model and enhance its accuracy, it is important to include additional data so that the model can be re-trained. The outcomes of this research show that ANNs have several advantages that make them a powerful tool to predict the pile's axial capacity.

\section{REFERENCES}

[1] L. Garland, G. Piscsalko, F. Rausche, and M. Hussein, "Monitoring quality assurance for deep foundations," Current Practices and Future Trends in Deep Foundations, pp. 222-238, 2004.

[2] B. Tarawneh, "Predicting standard penetration test $\mathrm{N}$-value from cone penetration test data using artificial neural networks," Geoscience Frontiers, vol. 8, no. 1, pp. 199-204, 2017.

[3] B. Tarawneh, "Pipe pile setup: Database and prediction model using artificial neural network," Soils and Foundations, vol. 53, no. 4, pp. 607-615, 2013.

[4] B. Tarawneh and R. Imam, "Regression versus artificial neural networks: predicting pile setup from empirical data," KSCE Journal of Civil Engineering, vol. 18, no. 4, pp. 1018-1027, 2014.

[5] O. Tatari, S. Sargand, T. Masada, and B. Tarawneh, "Neural network approach to condition assessment of highway culverts: Case study in Ohio," Journal of Infrastructure Systems, vol. 19, no. 4, pp. 409-414, 2013.

[6] B. Al Tarawneh, "Inspection, durability, and risk assessment of highway culverts," Ph.D. thesis, Ohio University, Athens, Ohio, 2005.

[7] T. Masada, S. Sargand, B. Tarawneh, G. Mitchell, and D. Gruver, "New inspection and risk assessment methods for metal highway culverts in Ohio," Transportation Research Record: Journal of the Transportation Research Board, no. 1976, pp. 141-148, 2006.

[8] T. Masada, S. Sargand, B. Tarawneh, G. Mitchell, and D. Gruver, "Inspection and risk assessment of concrete culverts under Ohio's highways," Journal of Performance of Constructed Facilities, vol. 21, no. 3 , pp. $225-233,2007$

[9] B. Tarawneh and M. Nazzal, "Optimization of resilient modulus prediction from FWD results using artificial neural network," Periodica Polytechnica, vol. 58, no. 2, pp. 143-154, 2014. 
[10] M. Ornek, M. Laman, A. Demir, and A. Yildiz, "Prediction of bearing capacity of circular footings on soft clay stabilized with granular soil," Soils and Foundations, vol. 52, no. 1, pp. 69-80, 2012.

[11] F. Nejad, M. Jaksa, M. Kakhi, and B. McCabe, "Prediction of pile settlement using artificial neural networks based on standard penetration test data," Computers and Geotechnics, vol. 36, no. 7, pp. 1125-1133, 2009.

[12] M. Abu-Kiefa, "General regression neural networks for driven piles in cohesionless soils," Journal of Geotechnical and Geoenvironmental Engineering, ASCE, vol. 124, no. 12, pp. 1177$1185,1998$.

[13] L. Khan and K. Decapite, "Prediction of pile set-up for ohio soils," Report No. FHWA/OH-2011/3, FHWA, U.S. Department of Transportation, 2011.

[14] W. Thompson, L. Held, and S. Say, "Test pile program to determine axial capacity and pile setup for the Biloxi Bay Bridge," Deep Foundation Institute, vol. 3, no. 1, pp. 13-22, 2009.

[15] V. Komurka, "Incorporating set-up and support cost distributions into driven pile design," Current Practices and Future Trends in Deep Foundations 125, Geotechnical Special Publications, ASCE/GeoInstitute, pp.16-49, 2004

[16] A. Dover and R. Howard, "High capacity pipe piles at San Francisco international airport," Deep Foundations Congress, Geotechnical Special Publication, ASCE, pp. 655-667, 2002.

[17] D. Holloway and D. Beddard, "Dynamic testing results, indicator pile test program, I-880, Oakland, California," in Proc. Deep Foundations Institute 20th Annual Members Conference and Meeting, Charleston, South Carolina, 1995, pp. 105-126.

[18] J. Antorena and T. McDaniel, "Dynamic pile testing in soils exhibiting set-up," in Proc. Deep Foundations Institute 20th Annual Members Conference and Meeting, Charleston, South Carolina, 1995, pp. 17-27.

[19] G. Goble, D. Cochran, and F. Marcucci, "Foundation design and evaluation for Winnemucca viaduct," Transportation Research Record, no. 884, pp. 37-45, 1982.

[20] F. Tavenas, " Load test results on friction piles in sand," Canadian Geotechnical Journal, vol. 8, no. 1, pp. 7-22, 1971

[21] T. Masters, "Practical neural network recipes in C++," Academic, San Diego, 1993

[22] M. Shahin, H. Maier, and M. Jaksa, "Data division for developing neural networks applied to geotechnical engineering," Journal of Geotechnical and Geoenvironmental Engineering, ASCE, vol. 18, no. 2, pp. 105-114, 2004.

[23] I. Flood and N. Kartam, "Neural networks in civil engineering: Principles and understanding," Journal of Computing in Civil Engineering, ASCE, vol. 8, no. 2, pp. 131-148, 1994.

[24] S. Tokar and P. Johnson, "Rainfall-runoff modeling using artificial neural networks," Journal of Hydrologic Engineering, ASCE, vol. 4 no. 3, pp. 232-239, 1999.

[25] M. Shahin, H. Maier, and M. Jaksa, "Predicting settlements of shallow foundations using artificial neural networks," Journal of Geotechnical and Geoenvironmental Engineering, ASCE, vol. 128, no. 9, pp. 785-793, 2002.

[26] R. Sonmez and J. Rowings, "Construction labor productivity modeling with neural networks," Journal of Construction Engineering and Management, vol. 124, no. 6, pp. 498-504, 1998.

[27] D. Stoutemyer, "Can the Eureqa symbolic regression program, computer algebra and numerical analysis help each other," Notices $A M S$, no. 60, pp. 713-724, 2013.

[28] B. Tarawneh, "Gene expression programming model to predict driven pipe piles set-up," International Journal of Geotechnical Engineering, 2018.

[29] D. Rumelhart and J. McClelland, "Parallel distributed processing," The PDP Research Group, The MIT Press, Foundations, Cambridge, vol. 1, no. 501f, 1986.

[30] J. Principe, N. Euliano, and W. Lefebvre, Neural and Adaptive Systems: Fundamentals through Simulations, Wiley, New York, N.Y, 1999

[31] N. Zavrtanik, J. Prosen, M. M. Tušar, and G. Turk, "The use of artificial neural networks for modeling air void content in aggregate mixture," Automation in Construction, vol. 63, pp. 155-161, 2015.

[32] H. Maier and G. Dandy, "Applications of artificial neural networks to forecasting of surface water quality variables: Issues, applications, and challenges," Artificial Neural Networks in Hydrology, Kluwer, Dordrecht, The Netherlands, pp. 287-309, 2000.

[33] M. Shahin, "Use of artificial neural networks for predicting settlement of shallow foundations on cohesionless soil," Thesis, University of Adelaide, 2003.
[34] K. Hornik, M. Stinchcombe, and H. White, "Multilayer feed forward networks are universal approximators," Neural Network, vol. 2, pp. 359-366, 1989.

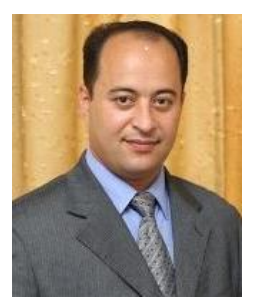

Anis S. Shatnawi received his Ph.D. degree in civil engineering from the University of Akron, Ohio, USA in 2001. He is currently an associate professor in the School of Engineering at the University of Jordan. He keep 20 years in research and development in the area of structural engineering. His research interests include computational and solid mechanics, dynamic of structural systems, and seismic-resistant structures. $\mathrm{He}$ has published dozens of papers in peer-reviewed journals and conferences proceedings. Dr. Shatnawi served as the Civil Engineering Department head, director of Engineering Projects Unit, and projects manager at the University of Jordan. He currently serves in many national scientific and technical committees in Jordan such as Jordanian National Building Code Council (JNBC), Technical Committee for Codes (TCC), Higher Structural Committee (HSC), and the Green Buildings Committee (GBC). He is also a member of numerous international and national societies including the American Society of Civil Engineers, Arab Society for Engineering Education and Quality Assurance, Jordanian Engineers Association, and Jordanian Society for Renewable Energy.

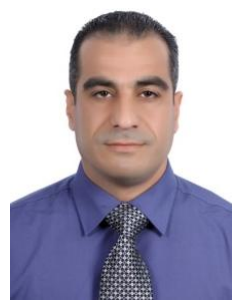

Wassel AL Bodour is an assistant professor of geotechnical engineering in the University of Jordan, Amman Campus, Jordan. He obtained his undergraduate degree in civil engineering (soil mechanics and foundations) in 1998 from Jordan University of Science and Technology. He also earned his MSc. degree in Geotechnical engineering from the same institute in 2005. Dr Wassel received his $\mathrm{Ph} . \mathrm{D}$. in geotechnical engineering from the University of Akron in 2010.

Dr. AL Bodour served as the assistant dean for accreditation and quality assurance at the University of Jordan from 2014 to 2015. He was an assistant professor at King Abdul Aziz University, Jeddah, Saudi Arabia from 2013 to 2014. Dr. AL Bodour had been a practicing engineer for 9 years and has been involved in multiple projects involving the analysis, design, and inspection of Seismic hazards, site response, soil dynamics, soil liquefaction, Landfills, anchored walls, landslide stabilization systems, earth slopes, MSE walls, instrumentations and deep soil mixing for earth and foundation support. Wassel has significant experience in the subsurface investigation, laboratory testing, analysis, and static and seismic design of earth structures and dikes. His research interests spans both soil mechanics and soil dynamics. Much of his work is to improve the design, performance, and understanding of the prevailing concepts in that field of engineering. Dr. AL Bodour is the author and co-author of several papers journal and conference papers in soil mechanics and dynamics.

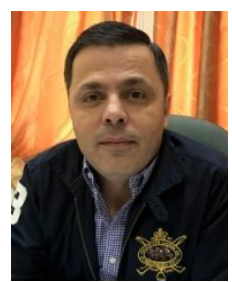

Mu'tasim Abdel-Jaber is the deputy dean of School of Engineering at the University of Jordan and he is a professor of civil engineering. He is a member of the slender research group in Oxford Brookes, UK. His research interests are lightweight steel structures, scaffold structures, and fiber reinforced structures. Dr. Abdel-Jaber is the author and co-author of several peer-reviewed journal papers in structural engineering.

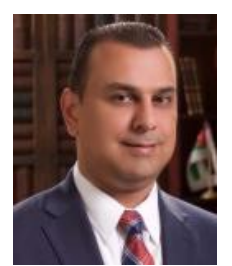

Bashar Tarawneh is a Ph.D. holder and a licensed professional engineer (P.E) who has more than eighteen years' experience in civil engineering. Currently, he is an associate professor of the civil engineering at the University of Jordan in Amman, Jordan. He has been teaching courses and conducting research in the area of civil and geotechnical engineering. His research interests include analytical aspects of soil-pipe interactions, inspection and risk assessment of structures, field performance and geotechnical analysis of shallow and deep foundations, settlements of shallow foundation on cohesionless soils, correlation of Standard Penetration Test (SPT) and Cone Penetration Tests (CPT), design and performance of Mechanically Stabilized Earth (MSE) Wall, application of artificial neural networks in civil engineering, resilient modulus prediction from FWD results, and ground improvement. 